\title{
La perspectiva religiosa y el uso de la lengua en Lutero
}

\author{
Juan Luis Monreal Pérez \\ Universidad de Murcia \\ jlmonreal@um.es
}

https://dx.doi.org/10.12795/futhark.2012.i07.07

\begin{abstract}
The contribution of Luther to the development of the vernacular languages is in so far worth mentioning as it has allowed that German would become a richer language and its use would spread. On the other hand, Luther realized about the necessary relation between classic and vernacular languages. In fact, it was necessary for Luther to write and to talk in German because he was convinced that languages were not an instrument to classify people according to their social status, but to communicate with everybody, and to give them access to texts, like the New and the Ancient Testament, originally written in other languages. His translation of the Bible is a good example concerning the use of the romance languages. He used all his linguistic, philological and theological skills so that the translation would achieve the goals of transferring the meaning and of making a communicative use of the language.
\end{abstract}

Keywords: Humanism, vernacular languages, German language, translation.

Resumen: La contribución de Lutero al desarrollo de las lenguas vernáculas ha sido relevante, porque ayudó al crecimiento y expansión de la lengua alemana y mostró la necesaria interrelación que debe existir entre lenguas clásicas y vernáculas. Lutero experimentó la necesidad de escribir y hablar en alemán convencido de que era el instrumento de comunicación que tenía para transmitir al pueblo alemán su obra y su pensamiento. Las lenguas no eran para él un puro signo de distinción social, sino la forma de establecer relaciones con la gente y de acceder al conocimiento original de los textos escritos en otras lenguas, como es el caso del Antiguo y Nuevo Testamento. Un buen ejemplo de la actitud coherente de Lutero en relación al uso de las lenguas fue el trabajo que llevó a cabo con la traducción de la Biblia, poniendo todo su saber hacer lingüístico, filológico y teológico en dicha tarea.

Palabras clave: Humanismo, lenguas vernáculas, lengua alemana, traducción.

\section{Introducción}

La Teología y la Sagrada Escritura constituyeron el núcleo central de la formación y dedicación profesional de Lutero. Toda su 
producción científica, a nuestro entender, debe ser leída desde esta perspectiva. La motivación religiosa está en la base no solo de su quehacer teológico y bíblico, sino también en su actividad en relación a la lengua y, más concretamente, a la lengua alemana, y de su aportación al campo de la traducción, mediante la versión de la Biblia al alemán y los escritos en los que aborda esta temática. En Lutero, pues, su perspectiva religiosa, su fe, se constituye en un elemento orientador de su vida personal, de su doctrina religiosa y de su quehacer profesional en los ámbitos de la lengua y de la traducción. Consecuencia de ello es la interrelación que establece entre todas las dimensiones de su vida (Cf. Oberman, 1992:363). A diferencia de lo que hacen otros humanistas españoles de la época, como Juan Luis Vives, Juan de Valdés y fray Luis de León, entre otros, que diferencian su perspectiva religiosa de su pensamiento sobre la lengua y la traducción por entender que son campos distintos, en el caso de Lutero todo está íntimamente relacionado, constituyéndose su modo de entender la fe en el hilo conductor y orientador de lo que piensa, cree y hace ${ }^{1}$.

Es más, la debatida cuestión de cuánto Lutero tenía de humanista también hay que revisarla desde su perspectiva religiosa en general y más concretamente desde las posiciones teológicas y escriturísticas que va adoptando en todo el proceso que le conduce a la Reforma Protestante. Las consideraciones anteriores nos permiten señalar que la perspectiva religiosa en Lutero envolvió todo su pensamiento y su obra y, por ello, cualquier análisis general o parcial que se haga de ellos, debe realizarse desde esta visión (Cf . Lilje, 1986:14-15) que constituye el objeto de análisis de este artículo.

La metodología que se utiliza para la construcción del texto se soporta principalmente sobre fragmentos de obras de Lutero que consideramos relevantes por sus contribuciones al objetivo fijado. Con carácter complementario también se recurre a textos de obras de otros autores que, a nuestro entender, ayudan a contextualizar, examinar y ver el alcance del pensamiento y de la obra de Lutero. Ello explica la abundancia y, al mismo tiempo, la necesidad de referencias que incorpora el texto, ya que éstas marcan su hilo discursivo, bien abriendo vías de reflexión, o, bien reforzando las

\footnotetext{
${ }^{1}$ Esta forma de entender y vivir la religión, por parte de Lutero, responde a la cultura del final de la Edad Media para la que la religión es el principio y el soporte de la conducta individual y de todo el edificio social (Cf. Villacañas, 2008:95-97).

Futhark 7 (2012)

Monreal, La perspectiva religiosa, 189-228
}

ISSN 1886-9300 
propuestas de ideas que realizamos. En el análisis de los fragmentos de texto que se hace, ha sido considerado tanto lo que dice el texto, fondo o contenido, así como la forma del mismo (Cf. Krippendorff, 1997; Alonso y Bravo:1994).

De la misma forma que hay que tener en cuenta la perspectiva religiosa de Lutero para estudiar su contribución a la lengua y a la traducción, también hay que enmarcar estos aspectos en el llamado Humanismo renacentista, cuestión que examinamos a continuación; de lo contrario nos faltarían los necesarios referentes culturales, sociales, políticos y religiosos para abordar adecuadamente el objetivo previsto.

\section{Lutero y el Humanismo renacentista}

En Alemania, tal como sucedió en los países europeos más impregnados del Humanismo renacentista, en los tres primeros decenios del siglo XVI se produjo un clima muy favorable hacia todo lo que suponía renovación, nuevos valores y recuperación de la cultura antigua a través del acceso a los estudios profanos, principalmente, los clásicos. Los humanistas en Alemania, como en otros países europeos (Cf. Vidal, 2008:32-37), también formaron un colectivo creciente, ávido de cambios y muy sensible a verse atraído hacia aquellos personajes que se pusieron a la cabeza de lo que representaban los valores más significativos del Humanismo renacentista (Cf. Lilje, 1986:39).

La vida de Lutero (1483-1546) transcurrió en este periodo histórico y cultural convulso, marcado por grandes acontecimientos de todo tipo, y en el que el propio Lutero no solo fue un receptor sin más de aquel clima general, sino que también su propia persona y obra le convirtieron en un actor especial del llamado acontecimiento de la Reforma. No cabe duda que el contexto histórico del mundo en el que vive Lutero tenía una animación intelectual propia. El último cuarto del siglo XV y la primera mitad del siglo XVI, fue una época marcada de acontecimientos extraordinarios que condicionaron el rumbo de la historia y estigmatizaron de alguna forma la vida de las personas.

Por todo ello, la época en la que vive Lutero hay que adscribirla al periodo renacentista, época de esplendor, apertura y renovación. Ello debería suponer que el pensamiento y la obra de 
Lutero tendrían que ser un reflejo de dicho período; es decir, que se le debería considerar como un buen representante de la época renacentista y que su pensamiento habría que encuadrarlo en el movimiento cultural Ilamado Humanismo renacentista. ¿Realmente esto es así? Sí y no. Ambas cosas al mismo tiempo. Sí, en el sentido de que nació y vivió en un ambiente que culturalmente respiraba Humanismo renacentista y que, cronológicamente hablando, precedió a la Reforma; fue coetáneo y próximo a Humanistas renacentistas tan preclaros como Zwinglio, Erasmo, Calvino, especialmente Melanchton ${ }^{2}$, entre otros, independientemente de las diferencias que más tarde se producirían entre él y algunos de éstos; su obra fue difundida y leída en ciudades alemanas que gozaron de un notable clima cultural renacentista, como Augsburgo, Nuremberg, Estrasburgo y Basilea; redescubrió la grandeza y dignidad natural del hombre, cuerpo y alma; criticó e, incluso, denigró y ridiculizó el sistema escolástico; dio al hombre un nuevo sentido de liberación; usó y defendió el uso de las lenguas vernáculas y, más concretamente el alemán, como medio de acceso de todo el pueblo cristiano al conocimiento de la Biblia.

Pero Lutero no participó de otros planteamientos humanistas renacentistas que caracterizaron el comportamiento de los representantes de dicho movimiento cultural, como fue el caso de Erasmo y Melanchton, por ejemplo. Buena muestra de tal actitud fue: su posición teológica de orientación hebraica y bíblica frente a la visión teológica humanista más antropocéntrica (Cf. Jansen, 1925: Parte Segunda, 265); su escaso interés por el desarrollo de las ciencias naturales y los estudios literarios y la dependencia total que estableció entre el hombre y Dios -hombre-siervo-, rompiendo la

\footnotetext{
${ }^{2}$ Resulta difícil analizar el perfil humanista de Lutero y no establecer su relación con Melanchton. El destino hizo que estas dos grandes figuras de la Reforma protestante alemana haya que asociarlas, puesto que las trayectorias de sus vidas y obras fueron básicamente en direcciones muy cercanas, aunque no idénticas, puesto que hay aspectos diferenciales entre ambos (Cf. Alcalá:1981:10). Los escritos tempranos de Melanchton se ven ya marcados por el espíritu humanista (Cf. Rupp, 1996:662), filosofía que mantendrá toda su vida, pese al difícil equilibrio que tuvo que tener para ser fiel en la básico, tanto a Lutero como al espíritu humanista (Cf. Pena, 2002:10). No obstante, la visión que Melanchton tiene del hombre se aleja suficientemente de la postura de Lutero actuando de freno respecto a ésta (Cf. Esteban 1997:34). El paso del tiempo no ha hecho sino resaltar la relevancia del espíritu humanista de Melanchton (Cf. Kusukawa, 1999:xi).
}

Futhark 7 (2012)

Monreal, La perspectiva religiosa, 189-228

ISSN 1886-9300 
posición central que el hombre ocupaba en el Humanismo renacentista -hombre centro del universo- (Cf. Lortz, 1963:320-321).

Esta doble situación que tuvo Lutero en relación al Renacimiento como movimiento cultural, le llevó -por una parte-, a respirar el ambiente renacentista, pero -por otra-, no asumió lo fundamental de dicha corriente de pensamiento: la visión humanista de la historia y la perspectiva de considerar al hombre como centro de la misma. Por tanto, Lutero, aún viviendo en la época del Renacimiento, no participa totalmente del espíritu humanista que la caracteriza. ¿Cómo se explica esta compleja situación de Lutero? A la luz de lo que ya se ha señalado en la Introducción y que constituye, en nuestra opinión, la explicación de la vida y obra de Lutero, hay que recurrir a su sentido religioso como interpretación de esta ambigüedad o, incluso, contradicción. Su modo de entender la fe y el hecho de situarse su vida a medio camino entre Medievo y Edad Moderna le hacen tener, por una parte, una visión del hombre propia del Medievo, es decir, sometiéndole a la soberanía de Dios; pero, por otra parte, la idea de la fe de Lutero también la encaja en la incipiente Edad Moderna, por la que dota al hombre de su dimensión subjetiva mediante la que establece su relación personal con Dios (Cf. Abellán, 1986:XXXV-XXXVI y Gómez Heras, 1986:37-38). Diciéndolo de otro modo, Lutero al sentirse atrapado entre las dos épocas, explica que no participara plenamente del Humanismo renacentista y que no se le pueda calificar como completamente moderno (Cf. Aranguren, 1986:9).

Debido a la doble faceta que la vida y obra de Lutero presenta, los humanistas alemanes vieron en él, en un primer momento, más que a un líder de la religión y la teología, a un gran defensor de aquellos valores humanistas considerados como elementos de regeneración de la vieja sociedad, tales como la estima por los estudios profanos clásicos, el rechazo de la teología especulativa y la necesidad de una nueva enseñanza que conllevara un cambio fundamental en la organización escolar (Cf. Grane, 1975:108-110).

Sin embargo, las expectativas que los humanistas alemanes depositaron en Lutero como hombre humanista, pronto se fueron desvaneciendo, a medida que el monje alemán se fue radicalizando en la cuestión religiosa y teológica y se produjera en Alemania la revolución religiosa. Ello supuso el desplazamiento del interés por el proyecto de reforma humanista y la entrada del conflicto religioso Futhark 7 (2012) Monreal, La perspectiva religiosa, 189-228

ISSN 1886-9300 
que consumó la Reforma Protestante. Esta situación hizo que el florecimiento humanista alemán se viera truncado y no lograra consolidar algunas de las reformas que anunciaba:

«Así, antes de mediados del siglo XVI, se extinguió la raza de los humanistas propiamente dichos $y$, con ella, la amplia dirección de su espíritu, su entusiasmo poético y su delicadeza artística y en su lugar vino una serie de profesores severos y dignos de aprecio, que, por lo general, mal retribuidos, poco honrados, desconocidos y frustrados, batallaron con desesperado valor contra la barbarie invasora; una serie de hábiles literatos e investigadores del lenguaje que explotaban la materia educativa de los clásicos en secas investigaciones especiales, ediciones de clásicos, trabajos gramaticales, arqueológicos, de historia literaria y crítica; una serie, finalmente, de eruditos que trabajaron en dos aspectos: como profesores tenían prelecciones ante auditorios escasos y desagradecidos, y, como escritores, editaban y explicaban las antiguas obras clásicas, y cultivaban ocasionalmente una erudita poesía escolar, que invadida por el mal gusto, no pudo poner un dique a la grosería invasora»

(Jansen, 1925: Parte Segunda, 181).

En resumen, se puede afirmar, que a partir de la segunda mitad del siglo XVI, los humanistas y el espíritu humanista se vieron desplazados en Alemania, debido al efecto de la "cuestión religiosa", que pasó a ocupar el lugar central de la vida de los alemanes, de sus Instituciones y de sus Poderes. Esta posición periférica que pasó a tener Alemania en la segunda mitad del siglo XVI en relación al Humanismo -como corriente cultural-, le hizo perder influencia en el mundo de las letras en relación al resto de países europeos que estuvieron más involucrados con dicho movimiento.

\section{Lenguaje y lenguas en Lutero}

Con carácter general hay que decir que desde los siglos XIV y XV en Europa empieza a desarrollarse la conciencia lingüística (Cf. Burke, 2006:23-24), tal como se pone de manifiesto por la utilización del latín como recurso lingüístico en ámbitos cultos, académicos y administrativos y por la presencia creciente del uso de las lenguas vernáculas que alcanzarán una considerable expansión ya en el curso del siglo XVI. Todos los humanistas, obviamente, consideraban que el latín les daba acceso al saber y les permitía

Futhark 7 (2012)

Monreal, La perspectiva religiosa, 189-228

ISSN 1886-9300 
universalizar el conocimiento y por ello hicieron uso del mismo. En cambio, en relación a las lenguas vernáculas, no todos se implicaron de la misma forma en el reconocimiento de dicho fenómeno y en el uso de las mismas. Las posiciones de los humanistas se situaron entre los siguientes extremos: haciendo uso exclusivo del latín como medio de producción científica y valorando positivamente las emergentes lenguas vernáculas, pero asignándoles un papel meramente secundario; o compartiendo el uso del latín como medio de comunicación con la población culta e ilustrada con el uso de las lenguas vernáculas para transmitir al pueblo no culto los contenidos de la nueva filosofía humanística.

Erasmo y Lutero son dos ejemplos de buenas prácticas en relación al uso de latín y de las lenguas vernáculas. Ambos convivieron con los dos sistemas lingüísticos (Cf. Carrera, 1988:9), pero se relacionaron con ellos de modo diferente. Por lo que se refiere a Erasmo recurrió a la lengua latina como la lengua culta, con posibilidad de comunicarse con la clase ilustrada en toda Europa y con la voluntad de asegurarse un mercado amplio de lectores para su producción científica; en definitiva, consideró al latín como segunda lengua materna. En cambio Lutero, aún valorando y conociendo bien el latín, le importó más el uso de la lengua como medio de comunicarse con el pueblo, en este caso el pueblo alemán (Cf. Oberman, 1992:361-363). Supo distinguir bien, cuándo debía usar el latín, siempre que se dirigía a lectores cultos, y cuándo debía usar el alemán, siempre que se dirigía al pueblo alemán creyente, que fue en la mayoría de los casos. En estos dos humanistas europeos hay, por tanto, dos estrategias lingüísticas diferentes, que repercutieron desigualmente en la consideración de la lengua.

Las lenguas ocupan un lugar relevante en la escala de valores de Lutero; éste fue el primer teólogo en considerar las lenguas como un instrumento básico para el acceso y el buen conocimiento del Evangelio, no escribiendo ni una sola línea que no estuviera motivada por su concepción de la fe (Cf. Lilje, 1986:14). Su perspectiva religiosa le hace ver la importancia que tienen las lenguas como instrumento para el entendimiento de la vida cristiana expresada en el evangelio, tal como nos relata en su escrito $A$ los magistrados de todas las ciudades alemanas, para que construyan y mantengan escuelas cristianas (1523):

«Cuanto mayor sea nuestro amor al evangelio mayor tendrá que ser nuestro celo por las lenguas; que no en vano 
ha querido Dios que su escritura se redactase sólo en dos lenguas, en hebreo el viejo testamento y en griego el nuevo. Ahora bien, si Dios no las ha despreciado sino que las ha preferido entre todas las demás como vehículo de su palabra, también nosotros tendremos que honrarlas sobre todas las restantes [...] Quede bien claro que, sin las lenguas, no será posible la recta conservación del evangelio. Las lenguas son la vaina en que se enfunda este puñal del Espíritu, son el cofre en el que se porta esta alhaja, la vasija en que se contiene esta poción, la cámara en que se guarda esta comida, las canastas -en conformidad con el mismo evangelio- que conservan el pan, los peces y los mendrugos de las sobras. Si -Dios no lo quiera- nuestro desprecio de esto condujera al extremo de abandonar las lenguas, no sólo habremos perdido el evangelio, sino que llegaremos a vernos imposibilitados al fin para hablar y escribir correctamente el latín, e incluso el alemán. Lo ocurrido en las universidades y conventos tiene que servirnos de argumento y de toque de atención: no sólo se ha olvidado en ellos el evangelio, también se ha corrompido el latín y el alemán: Las pobres gentes que allí están se han convertido en animales irracionales; no pueden hablar ni escribir correctamente el alemán ni el latín y hasta han perdido la razón natural»»

(Lutero, 2006:222- 223).

En esta crítica a la situación religiosa existente ${ }^{3}$, Lutero ofrece la útil visión que tiene de la relación entre las lenguas; en su opinión, éstas son diversas y de naturaleza distinta, siendo las clásicas el fundamento de las vernáculas. De hecho, el desarrollo y el conocimiento de las llamadas lenguas vernáculas, como es el alemán -entre otras-, necesitan a su vez del conocimiento de las lenguas clásicas.

Las lenguas no eran para Lutero un puro signo de distinción social, sino la forma de establecer relaciones con la gente y de

\footnotetext{
${ }^{3}$ Lutero, dada su habitual actitud radical, se excede al pensar que el universo católico, en su conjunto, despreciaba las lenguas, ya que como bien sabemos, muchas instituciones eclesiásticas y clérigos y religiosos fomentaron el uso y el desarrollo de éstas, como es el caso de fray Luis de León, quien aparte de conocer bien el hebreo, griego y latín, especialmente en su obra De los Nombres de Cristo nos muestra el gran conocimiento que tiene de la lengua castellana. Al agustino le importó mucho el buen uso de ésta, ya que era consciente que en esta lengua romance había cosas no bien escritas. Siempre mostró una permanente preocupación lingüística en toda su actividad literaria realizada en prosa y en romance, para que sus escritos hicieran un buen uso del castellano.
}

Futhark 7 (2012)

Monreal, La perspectiva religiosa, 189-228

ISSN 1886-9300 
acceder al conocimiento original de los textos escritos en otras lenguas, como es el caso del Antiguo y Nuevo Testamento. Además, la sensibilidad que tuvo hacia éstas le permitió, por una parte, saber administrar bien este gran capital, distinguiendo bien el uso que de las lenguas se debe hacer en cada momento; pero, por otra parte, le hizo también estar abierto de modo natural a la realidad de las lenguas vernáculas dominantes en la Europa de su tiempo.

Por todo lo anteriormente referido, el uso del alemán no le supuso a Lutero, como fácilmente podría pensarse, olvidar ni mucho menos rechazar el interés y la utilidad de las lenguas. Al contrario, éste se esforzó por explicar la conveniencia y la necesidad de aprender lenguas, tanto las clásicas como las vernáculas, bien para que los jóvenes adquirieran una buena formación como para que la palabra de Dios fuera conocida e interpretada correctamente, teniendo acceso a aquellas lenguas en las que la palabra de Dios fue escrita.

Debido a esto la contribución de Lutero al desarrollo de las lenguas vernáculas ha sido relevante, porque vio con claridad la necesaria interrelación que debe existir entre lenguas clásicas y vernáculas. En esta cuestión, Erasmo no consiguió estar a la altura de Lutero, ya que materializó toda su obra escrita siempre en latín y no fomentó directamente el uso de ninguna lengua vernácula. Por el contrario, Lutero apoyó y deseó la mayor expansión para las lenguas vernáculas, como dejó patente en su escrito sobre la Misa alemana y la ordenación del oficio divino:

«No estoy totalmente de acuerdo con quienes se atienen a una sola lengua y desprecian todas las demás. Porque me gustaría educar a la juventud y al pueblo de manera que también en los países extranjeros pudieran servir de utilidad a Cristo y conversar con la gente»

(Lutero, 2006:280).

\section{Lutero y el uso de la lengua alemana}

Lutero contribuyó a dar el salto necesario para fijación del alemán como lengua vernácula. Con su aportación la lengua alemana fue algo más de lo que era antes y ayudó a la labor que muchos hombres y generaciones de alemanes habían realizado antes que él para transitar desde los dialectos germanos a la unidad lingüística nacional. Lingüísticamente hablando, Lutero se situó en relación al alemán en una posición central y oficial -la de la Futhark 7 (2012) Monreal, La perspectiva religiosa, 189-228

ISSN 1886-9300 
Cancillería de Sajonia-, alejada de un dialecto en particular, y utilizó todas las variedades idiomáticas, de modo que todos los alemanes le entendieran ${ }^{4}$.

Ciertamente, Lutero sintió la necesidad de escribir y hablar en alemán convencido de que era el instrumento de comunicación que tenía para transmitir al pueblo alemán su obra y su pensamiento, por el gran poder que le atribuía a esta lengua para difundir los mensajes. Ello le llevó a tener, tanto cuando escribía como cuando hablaba, una sensibilidad muy agudizada para reconocer el efecto que en un determinado proceso de comunicación se ejercía sobre un destinatario concreto. Siempre tenía presente a quién se dirigía y en razón de ello organizaba el mensaje transmitiendo el contenido que quería compartir. Por eso intentó usar todos los recursos que la lengua y el lenguaje le ofrecían para conseguir sus objetivos. Se puede decir, expresado en la jerga del campo de la comunicación, que Lutero fue en la sociedad de su tiempo un gran experto en marketing y publicidad, gracias a la habilidad que tenía para conseguir el efecto perseguido.

Tal efectividad en el manejo de la lengua alemana se debía a que supo cómo transmitir empatía con lo que sentía y pensaba el pueblo alemán. No con los intereses del pueblo alemán en abstracto, sino muy en concreto; es decir, conocía bien las demandas y expectativas que tenían los diferentes grupos sociales alemanes en relación a cuestiones relacionadas con la religión y la Iglesia, tan necesitada de reforma.

Desde esta perspectiva, la lengua alemana hablada y escrita fue para Lutero su instrumento lingüístico habitual, tanto en los ambientes ilustrados como entre el pueblo sencillo, tal como nos lo expresa en uno de los pasajes de su escrito Charlas de sobremesa:

\footnotetext{
«El doctor Erasmo Alber, al ir a predicar al Margraviato (invitado por el Margrave Juan von Küstrin, 1537), rogó al doctor Martín Lutero le indicase la manera de predicar a los príncipes. Díjole el doctor: Todos tus sermones tienen
}

\footnotetext{
${ }^{4}$ Cf. R. Sala (1999:261): "Desde la traducción al alemán de la Biblia por Lutero hasta el siglo XVIII, el dialecto sajón de Meissen fue la lengua culta de Alemania, elevada a la categoría de «lengua nacional» por Gottsched. La influencia de Goethe sería decisiva para la posterior unificación del alto alemán y el alemán central y su conversión en la lengua literaria que hoy se conoce".
}

Futhark 7 (2012)

Monreal, La perspectiva religiosa, 189-228

ISSN 1886-9300 


\begin{abstract}
que apoyarse en la mayor sencillez; y no te fijes en los príncipes, sino en los simples, en los necios, en los toscos e ignorantes, y así alimentarás también a los príncipes. Si en mi sermón tuviera que fijarme en Felipe o en los otros doctores, obraría muy mal; pero predico sencillamente a los no instruidos, y esto gusta a todos. Sé griego, hebreo; pues bien, prescindo de todo eso cuando estamos reunidos los muy letrados. $Y$ es que a veces rizamos tanto el rizo, que Dios nuestro señor debe quedarse perplejo allá arriba»
\end{abstract}

(Lutero, 2006:436).

No cabe duda que el éxito que Lutero tuvo en la comunicación religiosa se explica porque siempre optó por el lenguaje sencillo, accesible a todos, fueran cultos o ignorantes. Su conocimiento de las lenguas y su saber teológico y escriturístico no le alimentaron la especulación, sino que fueron recursos que supo manejar bien para transmitir el mensaje cristiano al pueblo creyente. Esta actitud le llevó a tener una posición frontal contra el escolasticismo al fomentar éste la abstracción y la pura especulación en el discurso teológico.

No obstante y a pesar del valor comunicativo que Lutero atribuye a la lengua alemana, fue consciente de la funcionalidad del uso de la lengua y pensó que la elección de una u otra lengua debe responder, en última instancia, a la eficacia del objetivo que se quiere conseguir (Cf. Egido, 2006:278). Por ello, Lutero describe bien la funcionalidad del registro lingüístico en varios momentos de su obra, pero lo hace especialmente bien cuando trata un tema como la ordenación del servicio de la misa. Consciente de que cambios en este ámbito, sin previa reflexión, podían crear desconcierto y escándalo, el alemán se muestra especialmente cauteloso y aplica criterios distintos en el uso de la lengua en la celebración de la misa, tal como nos lo indica su escrito La «misa alemana» y la ordenación del oficio divino (1526):

«Hay tres formas de servicio divino y de la misa. En primer lugar, una latina que hemos publicado antes y que se llama Formula missae. No quiero suprimir ni cambiar esta forma: lo mismo que la hemos conservado hasta ahora, debe seguir siendo libre para acudir a ella cuando y como nos agrade o cuando lo aconsejen otros motivos. Porque en manera alguna quiero yo descartar la lengua latina del 
servicio divino, ya que creo que todo hay que realizarlo en vistas a la juventud. Si me fuese posible, y si el griego y el hebreo nos resultasen tan familiares como el latín y contasen con música y cantos tan bellos como los latinos, se debería celebrar la misa, leer y cantar todos los domingos respectivamente el alemán, latín, griego y hebreo.

[...]En segundo lugar, existe la misa y el servicio divino en alemán: es el orden que nos ocupa y que debe orientarse hacia los laicos sencillos. Pero debemos procurar que estas dos formas se celebren públicamente en las iglesias y a la vista de todo el pueblo. En él hay muchos que aún no creen ni son cristianos; están presentes como mirones para observar alguna novedad, exactamente igual que si celebrásemos el oficio divino entre turcos o paganos en una plaza pública o en el campo. No hay aquí todavía una asamblea ordenada y segura, en la que se pueda regir a los cristianos con las normas del evangelio. En este caso se trataría de un estímulo público a la fe y al cristianismo.

Pero la tercera forma, que debiera poseer las características de la genuina ordenación evangélica, no tendría que celebrarse con tanta publicidad en las plazas ni delante de todo el pueblo; sino que aquellos que con toda seriedad deseasen ser cristianos y confesar el evangelio de palabra y obra, deberían inscribirse nominalmente y reunirse por separado en una casa para la oración, para leer, bautizar, recibir el sacramento y practicar otras obras cristianas [...] Mas por el momento, no deseo organizar ni establecer semejante comunidad o asamblea, ya que todavía no dispongo de personas apropiadas y porque me doy cuenta de que no son muchos los que lo necesitan»

(Lutero, 2006:280-281).

El criterio que sigue Lutero para la elección de la lengua, latina o alemana, en el servicio religioso de la misa, obedece a razones fundamentalmente de pedagogía religiosa, es decir, hay que hacer que los actos litúrgicos sean accesibles a la comprensión del pueblo cristiano. El medio o instrumento, la lengua, es importante porque su función realmente lo es, pero supeditada a la razón religiosa. Esta es la filosofía que orienta a Lutero en su relación con la lengua, como ya se ha señalado anteriormente. 
El éxito de Lutero en relación a la lengua alemana se explica en buena parte, porque supo aprovechar bien todos los recursos disponibles que tuvo a su alcance, tanto los logros que el idioma alemán había ido consiguiendo a lo largo de su desarrollo previo, como sus recursos personales en las lenguas clásicas: «Lutero, en este aspecto, fue un privilegiado. La masa blanda aún y maleable de la lengua alemana le permitía libertades de todo género, casi ilimitadas» (García Yebra, 1979:33).

No le ha faltado a Lutero un amplio reconocimiento por esta labor realizada hacia la lengua alemana. Desde casi todos los frentes, si se excluye el de sus enemigos naturales (los papistas) que difícilmente podían sumarse a este reconocimiento expreso, ha habido a lo largo del tiempo testimonios claros tendentes a ensalzar la figura de Lutero por su contribución al desarrollo de la lengua alemana, como es el caso de su compatriota Federico Nietzsche cuando afirma que «la obra maestra de la prosa alemana es justamente la obra maestra de su máximo predicador: la Biblia ha sido hasta ahora el mejor libro alemán. Frente a la Biblia de Lutero, casi todo lo restante no es más que literatura; una cosa que no nació en Alemania, y que por eso no ha arraigado ni arraigará en los corazones alemanes como lo hizo la Biblia» (García-Villoslada, 1971:405).

Muchos de los reconocimientos a la labor de Lutero en pro de la lengua alemana le han considerado como el padre de la moderna lengua literaria alemana. Probablemente este calificativo es una exageración, como afirma Lilje, pero seguramente no lo es tanto, continúa diciendo, si se tiene en cuenta que el alemán -o, lo que es lo mismo, el alto alemán que devendrá en lengua literaria- es impensable al margen de Lutero (Cf. Lilje, 1986:13-14).

\section{Lutero y la traducción de la Biblia}

Un buen ejemplo de la actitud clara y coherente que tuvo Lutero en relación al uso de las lenguas, fue el trabajo que llevó a cabo con la traducción y la divulgación de la Biblia. En esta tarea, justamente, aplicó lo que defendió: traducir el Nuevo y Antiguo Testamento a la lengua alemana (alemanizar la Biblia, como Lutero solía decir), para que el pueblo alemán tuviera acceso a los sagrados textos, al evangelio (Cf. O'Neill, 1991:35). A esta tarea se dedicó buena parte de su vida, iniciándola en sus tiempos de Futhark 7 (2012) Monreal, La perspectiva religiosa, 189-228

ISSN 1886-9300 
profesor universitario en Wittenberg y continuándola hasta que le llegó la muerte. Toda la trayectoria docente, investigadora y divulgadora de Lutero estuvo muy marcada por su gran centro de interés: la Sagrada Escritura. Desde esta posición se entiende bien el principio que animó a Lutero a lo largo de toda su vida: sola scriptura, y como dice Egido,

«[...] entrañaba la convicción de ser ella la fuente de revelación, de gracia, de fe, de justificación, de santificación, de salvación, de vida cristiana, de organización eclesiástica, etc. Como confiaba un día a sus íntimos colaboradores, la Escritura sagrada 'se parecía a un bosque enorme con toda clase de árboles de los que se podían coger los frutos más variados, y que no había ningún árbol de este bosque al que no hubiera sacudido y del que no hubiera cortado un par de peras o manzanas'»

(Egido, 2006:34).

No cabe duda que para Lutero la traducción de la Biblia fue la gran empresa de su vida. Era consciente de que con ella ponía a disposición de todos los alemanes la palabra de Dios en su idioma, recuperando el cristianismo auténtico; sabía que esta tarea sería una de sus grandes contribuciones a la Reforma de la Iglesia. Suele reconocerse que esta traducción, aparte de hito en la historia teológica, es parte de la historia nacional de la cultura alemana (Cf. Peñalver, 1997:22).

Esta opinión positiva del papel de Lutero en relación a la traducción de la Biblia y de los efectos que ello produjo en el desarrollo de la lengua alemana es compartida por la mayoría de expertos (Cf. Audin, 1856:202). La mayoría de ellos opinan que la gran aportación de Lutero en su vida fue la traducción de la Sagrada Escritura al idioma de su pueblo. No cabe duda que la versión vernácula de la Biblia y la divulgación de la misma, ofreciéndola como única norma de fe, jugó un papel importantísimo en la fundación y establecimiento de la Iglesia luterana (Cf. GarcíaVilloslada, 1971:399).

A pesar del reconocimiento que Lutero merece por la traducción de la Biblia, es también el momento de señalar que dicho trabajo fue realizado desde la propia visión general que Lutero tenía sobre los distintos problemas y que en el enfoque o traducción de los mismos se refleja lógicamente su punto de vista. Esa situación no es particular al alemán, sino que está vinculada a la condición humana Futhark 7 (2012)

Monreal, La perspectiva religiosa, 189-228

ISSN 1886-9300 
y que su explicitación en el caso de Lutero permite entender los análisis críticos que ha recibido en relación a determinadas cuestiones. Esto es lo que hace Max Weber cuando a propósito de la concepción de Lutero sobre la profesión/trabajo (Beruf) dice de él «que leyó la Biblia con las gafas de su mentalidad global, ésta no sólo restó tradicionalista en el curso de su desarrollo entre 1518 y 1530 , sino que cada vez se volvió más tradicionalista» (Weber, 1998:144) ${ }^{5}$. Este texto de Weber confirma la orientación de este artículo, cuyo cometido es examinar cómo toda la actividad de Lutero relacionada con la lengua y la traducción estuvo condicionada por la perspectiva religiosa que guió fuertemente toda su trayectoria vital y profesional.

El trabajo de traducción Lutero lo desarrolló por partes distintas. Primero, abordó el Nuevo Testamento, tarea que inició en 1522 en la ciudad de Wartburg -aprovechando la soledad que le proporcionaba el período de reclusión al que fue sometido-, y que finalizó muy rápidamente gracias a los medios y apoyos con los que contó. Al cabo de seis meses, la traducción del Nuevo Testamento estaba en el mercado, bajo la iniciativa del impresor Lother y con el nombre en alemán Das neue Testament Deutsch. La valoración general del trabajo resultante de la traducción del Nuevo Testamento es que se trata de un texto con lenguaje nuevo y cercano al lector.

\footnotetext{
${ }^{5}$ M. Weber -partiendo de la idea de Lutero sobre la profesión como el cumplimento de los deberes intramundanos es en cualquier circunstancia el único camino para complacer a Dios, pues ellos y sólo ellos son la voluntad de Dios y, por tanto, toda profesión lícita tiene el mismo valor ante Dios-, reconoce que esta valoración ética de la vida profesional mundana fue una de las consecuencias más importantes de la Reforma protestante, y en especial de Lutero. Pero, a continuación añade que en Lutero el concepto de profesión restó vinculado al tradicionalismo. La profesión es lo que el ser humano ha de aceptar como orden divina, aquello a lo que ha de adaptarse: este matiz oculta la idea, también presente, de que el trabajo profesional es una (o más bien la) tarea puesta por Dios. Y el desarrollo del luteranismo ortodoxo subrayó este rasgo más aún. Resulta así, añade Weber, que mientras que al principio el tradicionalismo económico era el resultado de la indiferencia paulina, posteriormente fue la consecuencia de la fe cada vez más intensa en la providencia, que identifica la obediencia absoluta a Dios con la aceptación sin condiciones de la situación dada. Lutero no llegó por este camino a una conexión del trabajo profesional con principios religiosos que reposara sobre una base completamente nueva. La consideración de la pureza de la doctrina como único criterio infalible de la Iglesia fue cada vez más firme en Lutero tras las luchas de los años veinte del siglo XVI y detuvo por sí misma el desarrollo de nuevos puntos de vista en el terreno de la ética (Cf. Weber, 1998:141-147).
}

Futhark 7 (2012)

Monreal, La perspectiva religiosa, 189-228

ISSN $1886-9300$ 
Lutero procedió en dicho trabajo utilizando, por una parte, las fuentes originales en griego y, por otra, tomando como referencia otras fuentes, tales como la Vulgata en la edición griega de Erasmo y las versiones alemanas de la Biblia preexistentes que no eran pocas. El éxito obtenido fue enorme, tal como Egido refiere en la Introducción a las Obras de Lutero:

«El negocio fue estupendo. En una semana se agotó la primera abultada tirada de 3000 ejemplares y a los pocos meses apareció otra edición, segunda de una serie ininterrumpida hasta nuestros días. Al margen del negocio, que para nada interesaba a Lutero ni le beneficiaba en un penique, todos los alemanes que sabían leer contaron con un nuevo testamento inteligible, tan distinto de los anteriores dialectales o demasiado esclavos de la Vulgata».

(Egido, 2006:35).

Después del Nuevo Testamento, Lutero acometió la traducción del Antiguo Testamento. Esta tarea fue más larga (15231534). Necesitó de un equipo de colaboradores más expertos (entre ellos Melanchton), y fue más compleja desde el punto de vista de la traducción al alemán. Al igual que sucedió con el Nuevo Testamento, en la traducción del Viejo Testamento Lutero también utilizó fuentes de referencia como la traducción griega de los Setenta, la Vulgata latina, y versiones alemanas preexistentes.

Finalmente, en 1534 apareció el conjunto de la Biblia en lengua alemana, editada por las prensas de Luft, con más de un centenar de grabados y con Introducción y Notas del propio Lutero. El título general, que llena toda la portada, dentro de un marco renacentista, es el siguiente: Biblia das ist die. / gantze Reilige Schrifft Deudsch. / Mart. Luth. / Wittenberg. / Begnadet mit Kür / furst-licher zu Sacasen / freiheit. / Gedruckt durch Hans Lufft. / M. D. XXXIII. La difusión que empezó a tener obligó a hacer sucesivas ediciones, cosa que aprovechó Lutero para seguir revisándola y corrigiéndola. La edición de 1945 puede considerarse como la definitiva ${ }^{6}$.

Como era de esperar, la acogida que el público le dio a la obra de Lutero fue extraordinaria, teniendo una gran difusión, tanto en Alemania como en otros países, y estimándose que cerca de un

${ }^{6}$ En T. Egido (2006:60-61) se contiene una buena información sobre las Ediciones de

Futhark 7 (2012)

Monreal, La perspectiva religiosa, 189-228

ISSN 1886-9300 
millón de ejemplares pudieron haberse distribuido en los siguientes cincuenta años. éxito:

Varias razones se pueden aducir para la explicación de tal

a) Haber mejorado las traducciones preexistentes de la Biblia al alemán, porque las hubo y, además, Lutero las tuvo en cuenta a la hora de hacer la suya. Concretamente, existieron antes de la de Lutero, dieciocho versiones en Alemán, catorce en alto alemán y cuatro en bajo alemán (Cf. Collinson, 2004:58).

b) Haber utilizado en la traducción un lenguaje alemán universal (lenguaje común alemán) para hacerlo accesible a todos los alemanes, independientemente de las regiones donde viviesen que podían estar utilizando dialectos determinados.

c) Haber construido un idioma, resultado de haber incorporado, por una parte, la riqueza del idioma literario, pero -por otra-, también el habla corriente del pueblo. De aquí que en la lectura de la Biblia se sintieron cómodos, tanto los cultos e instruidos como la inmensa mayoría de los alemanes, con baja instrucción e, incluso, analfabetos.

En definitiva, el éxito de la obra llevada a cabo por Lutero hay que explicarlo por las anteriores razones y no porque la Biblia fuera desconocida anteriormente o porque ni Papas ni cardenales la leyeran, como afirmó Lutero; afirmación que lógicamente no se sostenía, teniendo en cuenta las ediciones anteriores de la misma, las traducciones alemanas preexistentes $y$, sobre todo, la universalidad que gozaba el libro sagrado por excelencia. Otra cuestión bien distinta es que a Lutero no le satisfacía el manejo que las anteriores traducciones alemanas hacían del alemán. Por diferentes motivos no le satisfacían a Lutero dichas traducciones: porque su lenguaje era tosco y dialectal y porque traducían literalmente de la Vulgata latina, conservando latinismos y hebraísmos de difícil comprensión, sin adaptarlos a la lengua popular germánica; $y$, sobre todo, porque en muchos pasajes no reflejaban el sentido teológico que él hubiera querido darles (Cf. García-Villoslada, 1971:399). Motivo éste ultimo que se constituye en fundamental, tal como se visto anteriormente, ya que para Lutero el uso de la lengua y el sentido de la traducción tienen que orientarse desde la perspectiva teológica/religiosa que él consideraba más idónea.

Futhark 7 (2012)

Monreal, La perspectiva religiosa, 189-228

ISSN 1886-9300 
Lógicamente, debido a los logros conseguidos por Lutero con la traducción de la Biblia al alemán, se le ha considerado como un maestro del lenguaje y como uno de los máximos contribuidores al desarrollo del alemán moderno. Esta faceta, independientemente de otras más discutibles, da legitimidad para considerarlo como hombre humanista.

Lutero con la traducción de la Biblia al alemán contribuye, pues, a que el alemán, como lengua vernácula, suba un peldaño, al igual que sucedió con el resto de lenguas vernáculas en Europa, ya que gracias a las traducciones que se realizaron de la Biblia se dio un impulso importante al desarrollo de las mismas. En este sentido cobra interés la valoración que hace Collinson de este hecho: «Casi todas las nacionalidades europeas emergentes se hicieron con sus Biblias en vernáculo durante el siglo $\mathrm{XVI}$; en todos los casos el hecho marcó el progreso de la lengua normalizada a expensas de los dialectos» (Collinson, 2004:61).

\section{Lutero y la traducción en el contexto de la Teoría de la traducción}

El desarrollo de la lengua se lleva a cabo a través de diferentes vías, siendo una de ellas la traducción. Esta actividad es un género literario con sus normas y finalidades propias. La traducción no es la obra, sino un camino hacia la obra; es un artificio técnico que acerca a la obra sin pretender jamás repetirla o sustituirla (Cf. Ortega, 1956:78/79; 88/89).

La traducción exige mucho conocimiento de las lenguas de origen y de llegada, y requiere suficiente sensibilidad y conexión con la realidad sociocultural del país en que se habla la lengua de destino (Cf. Oberman, 1992:205). La actividad de la traducción es todo un arte, basado en el conocimiento y en la experiencia, y el traductor -en última instancia-, tiene la obligación de producir un lenguaje que se adapte a toda una comunidad de hablantes. La traducción comporta complejidad, ya que requiere la debida comprensión de un texto para poderlo interpretar adecuadamente, tal como señala Gadamer:

«Por mucho que el traductor haya logrado introducirse y recrear los sentimientos del autor, la traducción no es una simple resurrección del proceso psíquico original 


\begin{abstract}
del escribir, sino una recepción del texto realizada en virtud de la comprensión de lo que se dice en él. No cabe duda que se trata de una interpretación y no de una simple correalización. Se proyecta, sobre todo una nueva luz procedente de la nueva lengua y destinada al lector de la misma. La exigencia de fidelidad que se plantea a una traducción no puede neutralizar la diferencia fundamental entre las lenguas. Por muy fieles que intentemos ser, nos encontraremos, sin embargo, en situaciones, en las que la decisión habrá de ser en cualquier caso inadecuada. Si queremos destacar en nuestra traducción un rasgo importante del original solo podemos hacerlo dejando en segundo plano otros aspectos o incluso reprimiéndolos del todo. Pero ésta es precisamente la clase de comportamiento que llamamos interpretación»
\end{abstract}

(Gadamer, 2005:464).

Lutero debía conocer las dos tradiciones anteriores y más significativas que en torno a la traducción se produjeron, y que se derivaron del trabajo de versión de obras clásicas escritas en griego al latín. Ambas tradiciones están representadas fundamentalmente por Cicerón y San Jerónimo.

Cicerón, por su parte, representando la tradición del clasicismo latino desprecia la traducción literal y el seguimiento pedestre del texto literal. El clásico latino entiende la traducción como un ejercicio de elocuencia, lo que le lleva a identificar lo esencial del texto original para posteriormente recrearlo en el idioma propio. Por tanto, la filosofía que orienta la labor traductora en Cicerón es la de trabajar la versión con sentido libre, nada de esclavitud ante el texto original (Cf. Calvo, 1984:70-71).

San Jerónimo, por otra parte, representando la tradición cristiana y autor de la versión Vulgata de la Biblia, se constituye en un referente teórico principal en el campo de la traducción a lo largo de toda la Edad Media y llega su influencia hasta la época moderna. La aportación de San Jerónimo va más allá de la de Cicerón, ya que éste generaliza el sentido de la traducción para todo tipo de textos, mientras que aquél diferencia el sentido de la traducción según de qué texto se trate. De aquí que el Santo distinga dos tipos de traducción: traducción libre para los textos profanos, al igual que Cicerón que lo hace con carácter general, y traducción literal para los textos sagrados, no confundiendo ésta con cualquier traducción pedestre o esclava de la letra. Ello, en su opinión, obligará al 
traductor a conocer muy bien la propia lengua para poder hacer la versión en las mejores condiciones (Cf. Calvo, 1984:71-72).

De todas formas, seguro que Lutero también conoció otras aportaciones al campo de la traducción que se produjeron desde la Baja Edad Media hasta los primeros años del Renacimiento por la vía de la traducción de textos sagrados al romance o por la versión de textos clásicos, principalmente del griego a la lengua latina ${ }^{7}$. En cualquier caso, en la época de Lutero la cuestión de la traducción era suficientemente debatida y se tenía plena conciencia de que ésta como arte que es había que realizarla en la forma y en el fondo de la mejor manera posible. Al respecto, tiene interés recordar la actividad que en aquel momento realizan eruditos de la traducción, como el ya mencionado Chysoloras, quien sostenía que la traducción literal (conversio ad verbum) era de escaso valor al afirmar cosas absurdas y pervertir el sentido original griego, o Estienne Dolet, quien publicó un opúsculo titulado La manière de traduire d'une langue en aultre [1540], o el caso de Luis Vives que expuso sus ideas sobre la traducción en el Libro III, Cap. 12 de su De ratione dicendi [1533]» (Cf. Breva-Claramonte, 1994:30, 36).

La dedicación de Lutero a la Teología y a la Sagrada Escritura le conduce a realizar hermenéutica bíblica, entendiendo esta tarea como el arte de comprender e interpretar los textos sagrados, la Biblia. A medida que Lutero acomete la Reforma, buena parte de su actividad intelectual se dedicará a la hermenéutica bíblica, tarea que se verá marcada por la forma de entender la fe, la nueva Teología de la Reforma.

En opinión de Lutero, la traducción/interpretación de la Biblia debe hacerse desde el propio texto, ya que la propia sagrada Escritura es sui ipsius interpres. No es necesario apoyarse en recursos exteriores, ni en la tradición ni en la doctrina oficial (dogma) para hacer su interpretación/traducción. Desde esta perspectiva, lo que Lutero hace es recurrir a la técnica traductora del

\footnotetext{
${ }^{7}$ Entre las contribuciones más significativas de este periodo, cercano a Lutero, tenemos las que representan eruditos de la traducción como el griego Chrysoloras (1355-1415), el italiano Guarino de Verona (1370-1460) y el también italiano Leonardo Bruni (1370-1444), quien al traducir textos de Platón, Jenofonte, Plutarco y Aristóteles lo hace con una bella factura, siguiendo las tradiciones de Cicerón y Petrarca y proclamando que una buena traducción debe hacerse bajo aquellos requerimientos que aseguren la calidad de la misma.
}

Futhark 7 (2012)

Monreal, La perspectiva religiosa, 189-228

ISSN 1886-9300 
sensus literalis, ya que a su entender la literalidad de la Escritura posee un sentido inequívoco y de algún modo, retoma la tradición traductora de san Jerónimo, al considerar que para los textos sagrados era conveniente utilizar la traducción literal (sensus literalis), aunque ésta no debe confundirse con cualquier traducción pedestre o esclava de la letra.

Sin embargo, el sensus literalis de la Escritura no debe aplicarse, en opinión de Lutero, a todos y cada uno de los fragmentos de la sagrada Escritura. Debe ser el conjunto de la Escritura el que guíe la comprensión de cualquier fragmento individual, igual que la comprensión del conjunto debe ser el resultado de la comprensión de lo individual (Cf. Gadamer, 2005:227). Este recurso circular ${ }^{8}$ llevó a la hermenéutica bíblica protestante a interpretar los aspectos individuales de un texto desde el sentido unitario derivado del conjunto de la sagrada Escritura. Pero, ¿a qué elemento unitario los hermenéuticos bíblicos protestantes recurren para la interpretación de los textos individuales de la sagrada Escritura? Precisamente, será la visión teológica de la fe protestante la que se utiliza como elemento unitario para la interpretación de cada uno de los textos individuales de la sagrada Escritura. El sentido de la fe protestante orienta, pues, la traducción que hace Lutero de la Biblia, mediante la aplicación de la técnica del sentido literal de la Escritura. Ello confirma cómo la perspectiva religiosa de Lutero, sustentada en su forma de entender la fe, se constituye en el hilo conductor que guía la traducción de la sagrada Escritura, al igual que también orienta su actividad en el ámbito de la lengua alemana, tal como se ha señalado anteriormente.

Lutero y todo su equipo de colaboradores pusieron todo su saber hacer lingüístico, filológico y teológico en la traducción de la Biblia. Todos ellos eran conscientes de la compleja tarea que estaban desarrollando y se entregaron en alma y cuerpo a la misma. Porque, por una parte, la traducción debía ser el reflejo más exacto de la literalidad de los textos originales a traducir y, por otra, el alemán debía de expresar en la riqueza de este idioma los contenidos originales, manteniendo la máxima fidelidad a la literalidad de los mismos. Difícil equilibrio conseguir. Siempre, los problemas vinculados a la traducción surgen de la articulación de

\footnotetext{
${ }^{8}$ Esta forma de relacionar circularmente lo particular y lo general fue tomada de la retórica clásica y lo que se hizo desde la hermeneútica bíblica protestante fue aplicar este procedimiento al campo de la traducción/interpretación de la sagrada Escritura.

Futhark 7 (2012)

Monreal, La perspectiva religiosa, 189-228
}

ISSN 1886-9300 
ambos elementos: del texto de partida (texto original) y del texto de llegada (texto traducido). Precisamente, la correcta interpretación (hermenéutica) $^{9}$ de ambos textos es la que hace que exista el menor número de inexactitudes y errores, puesto que todo traductor es intérprete. El ejemplo del traductor que tiene que superar el abismo de las lenguas muestra con particular claridad la relación recíproca que se desarrolla entre el intérprete y el texto con el soporte del lenguaje (Cf. Gadamer, 2005:465, 467).

No cabe duda que cuando el proceso hermenéutico es bien conducido permite acceder al intérprete al conocimiento del texto, en cuanto objeto, puesto que la hermenéutica no es otra cosa que la familiarización de lo extraño (Cf. Romo, 2007:20). Por ello, la teoría hermenéutica aporta a la traductología una visión, por la que del traductor se espera que recree el texto más desde su óptica que desde la del autor, que sugiera o insinúe lo que las palabras no llegan a decir (Cf. Bogomilova, 2004:19-20).

\section{Lutero y su obra Sendbrief vom Dolmetschen/Del arte de Traducir}

\section{Motivo que origina la obra}

Lutero afronta el problema de la traducción para defenderse y, al mismo tiempo atacar, a aquellos que le criticaron por cómo llevó a cabo la traducción de algunos textos bíblicos, concretamente el referido a la carta de los Romanos, 3, 28. Desde la fortaleza de Coburgo, donde estaba confinado para su seguridad y contra su voluntad, Lutero redacta la carta Misiva sobre el arte de traducir/ Sendbrief vom Dolmetschen $(1530)^{10}$ como reacción a la prohibición

\footnotetext{
${ }^{9}$ George Steiner, en su obra Después de Babel, describe con claridad el proceso a seguir en la traducción para que se asegure su consistencia hermenéutica: "El modelo esquemático de la traducción es el de un mensaje proveniente de una lengua-fuente que pasa a través de una lengua receptora, luego de haber sufrido un proceso de transformación. El escollo reside en el hecho evidente de que una lengua difiere de la otra, y para que el mensaje logre "pasar" es necesario que se dé esa transformación interpretativa que algunas veces es descrita, aunque no siempre con acierto, en términos de codificación y descodificación" (Steiner, 1981:44-45).

${ }^{10}$ El texto princeps de la carta que se utiliza en edición bilingüe Sendbrief vom Dolmetschen und Fürbitte der Heiligen (Carta sobre el arte de traducir y sobre la intercesión de los santos) se encuentra en la edición de Weimar de las obras completas de Martín Lutero: Werke. Kritische Geseamtausgabe. Weimar, 1883ss. Tomo 30/2 de la primera serie, pp. 627-646 y que apareció impreso en 1530 en varias Futhark 7 (2012) Monreal, La perspectiva religiosa, 189-228
}

ISSN $1886-9300$ 
que se hizo de su traducción del Nuevo Testamento en la Sajonia regida por el duque Jorge, motivada por los ataques descalificatorios que sufrió su obra por parte de su gran rival Jerónimo Emser (14781527). Éste encontró en dicha traducción muchísimas inexactitudes y, sin embargo, no tuvo ningún empacho en hacer una nueva versión de la obra, que sustancialmente coincidía con la de Lutero y que se declaró como preceptiva en Sajonia por su protector el duque Jorge. El escrito Misiva sobre el arte de traducir, bajo la forma literaria de epístola enviada a su amigo Wenceslao Link como respuesta a dos cuestiones que éste le plantea, ha sido la ocasión y la oportunidad de que Lutero nos transmitiera unas ideas sobre teoría de la traducción ${ }^{11}$.

El estilo de la epístola está marcado por un tono fuerte de agresividad ante aquellos que le critican, descalificándolos desde el inicio como ignorantes en materia de traducción.

El origen de la polémica que Lutero mantuvo con los papistas y que dio origen a la Misiva, residió en que Lutero añade "sólo por la fe», a su traducción de la Biblia Arbitramur hominen justificari ex fide absque operibus ${ }^{12}$, ya que así la lengua alemana, en su opinión, resulta lingüísticamente más ingeniosa y armoniosa con la lengua.

ediciones, y la que aquí sirve de fuente es la edición de Nürnberg, Johann Stüchs, 1530. La edición y traducción de la edición bilingüe ha sido hecha por Tobias Brandenberger y publicada por Caparrós Editores, 2002.

${ }_{11}$ Dada la importancia que este texto tiene para conocer el pensamiento de Lutero sobre la traducción, las citas textuales que se incorporan se hacen directamente del original alemán con su correspondiente traducción en español, utilizando al respecto la edición bilingüe anteriormente referenciada de Tobias Brandenberger.

${ }^{12}$ Esta traducción está en el origen de lo que Lutero entendía por libertad del hombre ante Dios y que alimentó la polémica Erasmo/Lutero en relación al libre albedrío. Esta cuestión es, en definitiva, la que explica las relaciones históricas entre estos dos grandes personajes del Humanismo y de la Reforma (Cf. Bello, 1983:50). En la concepción que Lutero tiene del libre albedrío se refleja su pesimismo antropológico, por su falta de confianza en el hombre que le lleva a establecer una antítesis entre la sociedad humana y el reino de Dios. Esta posición radical del agustino en una cuestión tan fundamental como ésta hizo que líderes reformadores notables marcaran sus diferencias con él, como es el caso de Calvino, quien "pese a partir de un indiscutible pesimismo teológico y afirmar el servo arbitrio natural (sí libertad extrínseca y no libertad intrínseca), tiene una mayor fe en las facultades humanas para desenvolverse en el ámbito temporal" (Rivera, 1999:56).

Futhark 7 (2012)

Monreal, La perspectiva religiosa, 189-228

ISSN 1886-9300 
La selección y lectura que hacemos, a continuación, de determinados fragmentos de dicha obra de Lutero y que guardan estrecha relación con la traducción, responde a que en dichos contenidos Lutero nos expone el procedimiento a seguir en este campo, así como los criterios que deben orientar este oficio.

\section{Procedimiento a seguir en la traducción}

Con carácter general, Lutero considera importante, desde la perspectiva de la traducción, que el texto original sea vertido al alemán, tal como se habla en esta lengua, siendo fiel a la literalidad del original. Esta cuestión la considera básica y, por ello, justifica el uso que ha hecho de la palabra solum en la versión alemana del texto Romanos, 3 , aunque dicha palabra no se halla en el texto latino y griego.

«Das ist aber die Art unser deutschen Sprache, wenn sie ein Rede begibt von zweien Dingenien, der man eins bekennet und das ander verneinet, so braucht man des Worts solum (allein) neben dem Wort nicht oder kein, als wenn man sagt: Der Baur bringt allein Korn und kein Geld. Nein, ich hab wahrlich itzt nich Geld, sondern allein Korn. Ich hab allein gessen und noch nicht getrunken. Hast du allein geschrieben und nich urberlesen? Und dergleichen unzählige Weise in täglichen Brauch.

In diesen Reden allen, ob's gleich die lateinische oder griechische Sprach nicht tut, so tut's doch die deutsche und ist ihr Art, da $\beta$ sie das Wort allein hinzusetzt, auf da $\beta$ das Wort nicht oder kein deste volliger und deutlicher sei. Denn wiewohl ich auch sage: Der Baur bringt allein Korn und Kein Geld, so laut doch das Wort kein Geld nicht so vollig und deutlich, als wenn ich sage: Der Baur bringt allein Korn und Kein Geld. Und hilft hie das Wort allein dem Wort Kein soviel, $\mathrm{da} \beta$ es ein vollige deutsche, klare Rede wird; denn man muß nicht die Buchstaben in der lateinischen Sprachen fragen, wie man soll deutsch redden, wie [diese Esel tun, sondern man muß die Mutter im Hause, die Kinder auf der Gassen, den gemeinen Mann auf dem Markt drum fragen und denselbigen auf das Maul sehen, wie sie redden, und darnach dolmetschen, so verstehen sie es denn und merken, da $\beta$ man deutsch mit inn' redet»

(Luther, 1883:76, 78, 80).

[ Y esta es la manera de nuestra lengua alemana: cuando se habla de dos cosas, afirmándose una y negándose 
la otra, entonces se utiliza la palabra solum (sólo) al lado de la palabra no o ninguno. Así cuando se dice El campesino trae sólo grano, y no dinero. No, ahora de verdad no tengo dinero, sino sólo grano. Sólo he comido, y no he bebido todavía. ¿Sólo has escrito, y no repasado? Y así de infinitas maneras, según la costumbre diaria.

Aunque la lengua latina o griega en todas estas expresiones no lo hace, sí lo hace la alemana, y es su manera la de añadir la palabra sólo, para que la palabra no o ninguno quede más completa y nítida. Pues si bien puedo decir también El campesino trae grano y no dinero, las palabras $y$ no dinero no suenan tan completas y claras como cuando digo El campesino trae sólo grano, y no dinero, ayudando aquí la palabra sólo a y no para que resulte una sentencia completa, clara, alemana».]

(Lutero, 2002:77, 79).

Lutero, al recibir del lado católico fuertes críticas por su traducción de Romanos 3, responde acusando a los papistas de reacios a aceptar cualquier traducción que no refuerce la fe inmovilista, es decir, que suponga alguna variación con respecto al texto original. Para Lutero es un objetivo primordial no apartarse del texto original y que la versión del mismo al alemán sea un texto claro $y$ bien construido en esta lengua

«Also habe ich hie Roma. 3 fast wolh gewi $\beta$ t, da $\mathrm{im}$ lateinischen und griekischen Text das Wort solum nicht stehet und hätten mich solchs die Papisten nich dürfen lehren. Wahr ist's. Diese vier Buchstaben so I a stehen nicht drinen, welche Buchstaben die Eselsköpf ansehen wie die Kuh ein neu Tor, sehen aber nicht, da $\beta$ gleichwohl die Meinung desText in sich hat, und wo man's will klar und gewaltiglich verdeutschen, so gehoret es hinen, denn ich habe deutsch, nicht lateinisch noch griekisch reden wöllen, da ich deutsch zu reden im Dolmetschen furgenommen hatte»

(Luther, 1883:76).

[«Aquí, en Romanos 3, sabía yo perfectamente que en el texto latino y griego no se halla la palabra solum, y los papistas no habrían tenido que enseñarme tal cosa. Es verdad. No están ahí dentro estas cuatro letras $s o$ l a, que las cabezas de burro están mirando como la vaca un nuevo portal. Pero no ven que sí corresponden al sentido del texto, y que si se quiere llevar clara y perfectamente al alemán, tienen 


\begin{abstract}
que estar ahí -y yo he querido hablar alemán, no latín ni griego, ya que me había propuesto hablar alemán en la traducción»]
\end{abstract}

(Lutero, 2002:77).

\title{
Criterios para la traducción
}

Lutero aprovecha parte de la Misiva sobre el arte de traducir para señalar determinados criterios que conviene tener en cuenta a la hora de traducir y que él -en su caso-, ha intentado llevar a la práctica; criterios que pueden expresarse de la forma siguiente:

- Responsabilidad en este oficio. Lutero sabe que el oficio de traductor requiere de especiales cualidades para su buena práctica. En su opinión, aquellos que no han tenido experiencia en este campo, difícilmente lo pueden valorar y llevar a cabo:

«Ich wei $\beta$ wohl, und sie wissen's weniger denn des Müllners Tier, was fur Kunst, Fleiß, Vernunft, Verstand zum guten Dolmetscher gehöret, denn sie haben's nicht versücht»

(Luther, 1883:58).

[ YYo sé bien cuánto arte, diligencia, razón y discreción necesita el buen traductor, y ellos lo saben menos que el animal del molinero, pues no lo han probado»]

(Lutero, 2002:59).

- Calidad de la traducción. Lutero considera que para hablar de calidad en la traducción es necesario que la versión del texto en la lengua de llegada, en este caso el alemán, se produzca en términos de pureza y claridad. Tarea, por otra parte, no exenta de gran dificultad:

«Ich hab mich des gleflissen in Dolmetschen, daß ich rein und klar Deutsch geben möchte. Und ist uns wohl oft begegnet, da $\beta$ wir vierzehen Tage, drei, vier Wochen haben ein einiges Wort gesücht und gefragt, habens dennoch zuweilen nicht funden»

(Luther, 1883:74).

[«Al traducir, me esforcé por ofrecer un alemán puro y claro. $Y$ a menudo nos ha tocado buscar y preguntar por 
una sola palabra durante dos, tres, o cuatro semanas, y en ocasiones sin poderla encontrar»]

(Lutero, 2002:75).

- Pensar en la lengua a traducir. La traducción debe mirar a las dos orillas de referencia, a la lengua de origen del texto y a la lengua de destino del texto, para que el proceso traductológico tenga la calidad requerida; sin embargo, en la práctica se producen con frecuencia desequilibrios en la traducción al otorgarle mayor vigilancia hermeneútica a una lengua en detrimento de la otra. En el caso de Lutero confiesa, por una parte, su fidelidad a los textos originales en los que fueron escritos los libros sagrados; y, por otra, declara verter los textos originales a la lengua alemana hablada, tal como realmente el pueblo la habla:

«[...] denn ich habe deutsch, nicht lateinisch noch griekisch reden wöllen, da ich deutsch zu reden im Dolmetschen furgenommen hatte [...] denn man muß nicht die Buchstaben in der lateinischen Sprachen fragen, wie man soll deutsch redden, wie [diese Esel tun, sondern man mu $\beta$ die Mutter im Hause, die Kinder auf der Gassen, den gemeinen Mann auf dem Markt drum fragen und denselbigen auf das Maul sehen, wie sie redden, und darnach dolmetschen, so verstehen sie es denn und merken, daß man deutsch mit inn' redet»

(Luther, 1883:76, 78, 80).

«[...] -y yo he querido hablar alemán, no latín ni griego, ya que me había propuesto hablar alemán en la traducción [...] No hay que preguntar a las letras latinas cómo se debe hablar alemán, que es lo que hacen estos asnos, sino que hay que preguntárselo a la madre en casa, a los niños en la calle, al hombre común en el mercado y mirarles bien a la boca para ver cómo hablan, y traducir según esto; así lo entienden y se dan cuenta de que se está hablando alemán con ellos»]

(Lutero, 2002:77, 79, 81).

- Dificultad de conseguir la perfección en la traducción. Lutero reconoce varias veces en su obra la dificultad que entraña la labor de verter un texto a la lengua de destino, concretamente al alemán, sobre todo cuando se fija como objetivo fundamental que la traducción a esta lengua corresponda con la lengua, tal como se habla. La experiencia larga y esforzada de Lutero en la tarea de la 
traducción hace creíble su testimonio que atestigua la dificultad de conseguir la perfección en esta actividad:

«Als wenn Christus spricht: «Ex abundantia cordis os loquiturs Wenn ich den Eseln soll folien, die werden mir die Buchstaben furlegen und also dolmestchen: Aus dem Uberflu $\beta$ des Herzen redet der Mund. Sage mir, ist das deutsch geredt? Welcher Deutscher verstehet solchs? Was ist Uberfluß des Herzen fur ein Ding? [...] Sondern also redet die Mutter im Haus und der gemeine Mann: Wes das Herz voll ist, des gehet der Mund ubre. Das heißt gut deutsch geredt, des ich mich geflissen und leider nicht allwege erreicht noch troffen habe, denn die lateinischen Buchstaben hindern aus der Maßen sehr, gut deutsch zu reden»

(Luther, 1883:80, 82).

[«Así cuando dice Cristo: «Ex abundantia cordis os loquitur» Si tengo que seguir a los asnos, me presentarán las letras y traducirán: De la abundancia del corazón habla la boca. Dime: ¿es esto hablar alemán? ¿Qué alemán entiende tal cosa? ¿Qué será la abundancia del corazón? [...] La madre en casa y el hombre común hablan así: De lo que está lleno el corazón, rebosa la boca. Esto es hablar buen alemán, y en ello me he esforzado, aunque, desgraciadamente, no siempre lo he conseguido ni alcanzado, pues las letras latinas dificultan en extremo hablar buen alemán»]

(Lutero, 2002:81, 83).

- Diligencia en la actividad de la traducción. La actitud de Lutero en su trabajo de traductor de la Biblia es de cumplimiento con lo que requiere esta tarea, tanto en términos de dedicación como de cualificación. Lutero, aunque no es un profesional de este oficio, sin embargo sí se entrega a esta actividad durante los años que comprometió en la traducción de la Biblia como si realmente lo fuera, aunque sin obtener beneficios económicos ni por la traducción, ni por la difusión (Cf. Moreno, 2008:45) que se hizo de la misma, a diferencia de lo que sí hizo Erasmo durante su vida, quien logró llevar una vida económica independiente, gracias a su gran producción científica y divulgadora:

«Das kann ich mit gutem Gewisen zeugen, daß ich meine höchste Treu und Flei $\beta$ drinnen erzeigt und nie kein falsche Gedanken gehabt habe, denn ich habe keinen Heller dafur genommen noch gesücht noch damit gewonnen, so hab ich meine Ehre drinnen nicht gemeinet, das weiß Gott, 
mein Herr, sondern hab's zu Dienst getan den lieben Christen und zu Ehren einem, der droben sitzet, der mir alle Stunde soviet Guts tut, da $\beta$, wenn ich tausendmal soviel und fleißig gedolmetscht, dennoch nicht eine Stunde verdienet hätte zu leben oder ein gesund Auge zu haben»

(Luther, 1883:92).

[«Puedo afirmar con buena conciencia que he puesto en ello mi máxima fidelidad y diligencia y nunca he tenido ningún pensamiento falso -pues no he aceptado, buscado ni ganado un centavo por ello. Tampoco he procurado en ello mi honor, y Dios mi señor lo sabe; lo he hecho en servicio de los queridos cristianos, y en honor de quien está sentado arriba, quien me hace a toda hora tanto bien que, aun habiendo traducido mil veces más o con mil veces más diligencia, no merecería vivir ni una hora o tener un ojo sano»]

(Lutero, 2002:93).

- Fidelidad al texto original. El criterio de fidelidad al texto original constituye para Lutero el hilo conductor que orienta su traducción de la Biblia. Sin embargo, el criterio de fidelidad al texto original no es incompatible con la flexibilidad que a veces requiere la traducción de un texto, sin que ello suponga apartarse libremente del mismo:

«Doch hab ich wiederum nicht allzu frei die Buchstaben lassen fahren, sondern mit großen Sorgen samt meinen Gehülfen drauf gesehen, daß, wo etwa an einen Ort gelegen ist, hab ich's nach den Buchstaben behalten und bin nicht so frei davon gangen»

(Luther, 1883:94).

[«Por otro lado, no he soltado demasiado libremente las letras; con mis colaboradores hemos procurado muy cuidadosamente mantenernos fieles a ellas donde hiciera falta sin apartarnos tan libremente»]

(Lutero, 2002:95).

La conveniencia puntual de apartarse de la traducción literal de un texto viene requerida, en opinión de Lutero, por la exigencia de verter el texto adecuadamente al alemán:

«Darum mu $\beta$ ich hie die Buchstaben farhen lassen und forschen, wie der deutsche Mann solchs redet, welchs 
der ebräische Mann Isch Hamudoth redet. So finde ich, daß der deutsche Mann also spritcht: Du lieber Daniel, du liebe Maria oder du holdselige Magd, du niedliche Jungfrau, du zartes Weib und dergleichen. Denn wer dotmetschen Hill, muß große Vorrat von worten haben, daß er die wohl könne haben, woe ins an allen Orten nicht lauten will»

(Luther, 1883:88, 90).

[«Por ello, tengo que prescindir aquí de las letras y averiguar cómo expresa el hombre alemán aquello que el hombre hebreo Ilama isch hamudoth. Entonces encuentro que el hombre alemán habla así: querido Daniel, querida María, o: agraciada muchacha, encantadora doncella, dulce mujer, etc. Quien ha de traducir debe tener un gran tesoro de palabras para tenerlas a mano, cuando alguna no quiera sonar bien en absoluto»]

(Lutero, 2002:89, 91).

En la aplicación general de este criterio, Lutero sigue la tradición de san Jerónimo quien no confundió la traducción literal en los libros sagrados con la traducción pedestre o esclava de la letra. Sin embargo, hay algo importante que separa a Lutero de san Jerónimo: el interés especial de Lutero por traducir la Escritura al alemán de forma clara y comprensible para todo el pueblo alemán, no preocupándole tanto la forma literaria como la comprensión del mismo por todos los alemanes, independientemente de su nivel cultural. En cambio, san Jerónimo, sí procuró que su uso del latín estuviera al nivel de la gente culta de su tiempo, dándole -por tantola mejor forma literaria posible.

La convicción que Lutero tiene de la bondad de los mencionados criterios para el arte del buen traducir es lo que explica la belicosidad que muestra hacia los que él considera que no siguen las buenas prácticas de la traducción. Al respecto dice:

«Wenn ich, D. Luther, mich hätte mügen des versehen, da $\beta$ die Papisten alle auf einen Haufen so geschickt wären, daß sie ein kapitel in der Schrift künten recht und wohl verdeutschen, so wollt ich furwahr mich der Demut haben finden lassen und sie um Hilf und Beistand gebeten, das Neue Testament zu verdeutschen. Aber dieweil ich gewüßt und noch vor Augen siehe, da $\beta$ ihr' keener rechtwei $\beta$, wie man dolmetschen oder deutsch reden soll, hab ich sie und mich solcher Mühe uberhaben. Das merkt man aber wohl, da $\beta$ sie aus meinem Dolmetschen und Deutsch lernen

Futhark 7 (2012)

Monreal, La perspectiva religiosa, 189-228

ISSN 1886-9300 
deutsch redden und schreiben und stehlen mir also meine Sprache, davon sie zuvor wenig gewißt, danken mir aber nicht dafur, sordern brauchen sie veil liebre wider nicht. Aber ich gann es ihn' wohl, denn es tut mir doch sanft, da $\beta$ ich auch meine undankbare Jünger, dazu meine Feinde, reden gelehrt habe»

(Luther, 1883:56).

[«Si yo, el doctor Luther, hubiera podido sospechar que todos los papistas juntos fueran tan peritos como para llevar al alemán correcta y adecuadamente un capítulo de la Escritura, en verdad habría sido tan humilde que les habría pedido ayuda y apoyo para traducir el Nuevo Testamento. Pero les he dispensado a ellos y a mí de tal tarea, ya que sabía y tengo presente que ninguno de ellos sabe bien cómo hay que traducir o hablar alemán. Sí se nota bien que ellos aprenden a hablar y a escribir alemán de mi traducción y de mi alemán, robándome así mi lengua, de la que antes casi no tenían idea; pero no me lo agradecen, sino que prefieren usarla en mi contra. Yo se lo concedo de buena gana, pues me agrada haber enseñado a hablar a mis discípulos desagradecidos, aun a mis enemigos»]

(Lutero, 2002:57).

Esta incapacidad de los papistas para traducir de modo acertado, tal y como Lutero cree que hay que hacerlo, la menciona, una y otra vez, cuando señala aspectos concretos relacionados con la traducción, como ponen de manifiesto los siguientes fragmentos:

«Und wenn ich sie hätte sollen fragen, wie man die ersten zwei Wort Matthei I, Liber generationis, sollte verdeutschen, so hätte ihr keiner gewißt, gack dazu zu sagen» (Luther, 1883:58-60).

[ $Y$ si les hubiera tenido que preguntar cómo se deben llevar al alemán las dos primeras palabras de Mateo I, Liber generationis, ninguno de ellos habría sabido decir ni $m u$ al respecto»] (Lutero, 2002:57).

«Ich wollt noch gern den Papisten ansehen, der sich' erfur tät und etwa eine Epistel St. Pauli oder einen Propheten verdeutschet. Sofern daß er des Luthers Deutsch und Dolmetschen nicht dazu gebraucht, da sollt man sehen ein fein , schön, loblich Deutsch oder Dolmetschen» (Luther, 1883: 60). 
[«No obstante, me gustaría ver al papista que se esforzara y tradujera, por ejemplo, una epístola de San Pablo o a un profeta. Caso de que no recurra para ello al alemán y a la traducción de Luther, iqué lengua alemana o traducción elegantes, hermosas, admirables se verán!»] (Lutero, 2002:61).

Por todo ello, Lutero se rebela ante la ingratitud de los teólogos a su labor de traducción realizada, para lo cual tiene en cuenta el recurso retórico que ya en su día utilizó san Pablo ${ }^{13}$ :

«Denn wir wöllen nicht der Papisten Schuler noch Jünger, sondern ihre Meister und Richter sein, wöllen auch einmal stolziern und pochen mit denn Eselsköpfen, und wie Paulus wider Seine tollen Reiligen sich rühmet, so Hill ich mich auch wider diese meine Esel rühmen. Sie sind Doctores? Ich auch. Sie sind gelehrt? Ich auch. Sie sind Prediger? Ich auch. Sie sind Theologi? Ich auch. Sie sind Disputatores? Ich auch. Sie sind Philosophi? Ich auch. Sie sind Dialectici? Ich auch. Sie sind Regenten? Ich auch. Sie sind Schreiben Bücher? Ich auch»

(Luther, 1883:66).

[«Es que no queremos ser alumnos ni discípulos de los papistas, sino sus maestros y jueces. También queremos, por una vez, ser orgullosos y alardear con las cabezas de burro; y de la misma manera que San Pablo se precia ante sus locos santos, así quiero yo preciarme ante estos mis burros. ¿Que ellos son doctores? ¡Yo también! ¿Que son sabios? ¡Yo también! ¿Que son sacerdotes? ¡Yo también! ¿Que son teólogos? ¡Yo también! ¿Que saben disputar? ¡Yo también! ¿Que son dialécticos? ¡Yo también! ¿Que son filósofos? ¡Yo también! ¿Que son profesores? ¡Yo también! ¿Que escriben libros? ¡Yo también!»]

(Lutero, 2002:67).

\section{Prioridad de Lutero en la traducción}

\footnotetext{
${ }^{13}$ El texto de san Pablo es el siguiente, según la Biblia de Jerusalén: "En cualquier cosa en que alguien presumiere -es una locura lo que digo- también presumo yo. ¿Que son hebreos? También yo lo soy. ¿Que son israelitas? ¡También yo! ¿Son descendencia de Abraham? ¡También yo! ¿Ministros de Cristo? (¡Digo una locura!) ¡Yo más que ellos! (San Pablo, Segunda Epístola a los Corintios: Capítulo 11, 21-22 (Biblia de Jerusalén, 1967: 1555).
}

Futhark 7 (2012)

Monreal, La perspectiva religiosa, 189-228

ISSN 1886-9300 
La prioridad principal que se fija Lutero en la tarea de la traducción es la de hacer que su lenguaje sea accesible para todos los sectores de la población alemana, independientemente de las clases o estamentos sociales o del lugar donde se viva a lo largo de toda la geografía en que se habla el alemán. Por ello, el prototipo lingüístico de Lutero es el alemán de uso corriente, el de mayor vitalidad $^{14}$. De aquí que el objetivo primordial de Lutero al traducir la Biblia era que el texto sagrado llegara al máximo de sectores sociales.

La recepción de la traducción que Lutero hace de los libros sagrados en alemán produce abundantes críticas ante las que responde con argumentaciones no solo lingüisticas sino también teológicas, debido a la relación que Lutero establece entre perspectiva religiosa/doctrina y lengua y traducción, como ya hemos señalado. Por ello no extraña el hecho de que Lutero tuviera en vida tantos detractores ${ }^{15}$. En este clima de críticas y detractores se entiende el proverbio tradicional alemán que el propio Lutero interpreta en su carta y que dice: «Wer am Wege bauet, der hat viel

\footnotetext{
${ }^{14}$ Al respecto, Martín de Riquer y José María Valverde consideran que la contribución de Lutero a la lengua es más una cuestión de lenguaje que una cuestión idiomática. Desde esta perspectiva es cómo éstos valoran el uso popular que Lutero hace de la lengua hablada alemana: "El lenguaje de Lutero es exagerado y dramático, siempre va ad hominen, sin importarle las contradicciones de términos ni la visible discutibilidad de sus sofismas [...] Cierto que no pretendió ser "escritor», y aun despreció la literatura y las «bellas letras» -y el latín, por más que parte de su vasta obra estuviera escrita en tal lengua, con eficacia aunque sin elegancia retórica-; pero su replanteamiento religioso, su "reforma del cristianismo", traía -de paso- una revolución literaria, porque era la irrupción de un sentir que requería una expresión más directa, viva y compleja que el lenguaje renacentista disponible" (Riquer y Valverde, 1984:5)

${ }^{15}$ Tampoco sorprende que los escritos de Lutero encontraran resistencia en los llamados adversarios frontales a su doctrina como en aquellos que compartían parte de sus planteamientos de reforma, pero que en materia de fe se fueron alejando de él, a medida que se fue radicalizando, como fue el caso de Erasmo. Un buen testimonio de esta situación queda reflejado en el siguiente pasaje: "Entre tanto, las tesis de Lutero difundidas rápida y extensamente en su traducción alemana, estaban ejerciendo una influencia profunda; y como en ellas andaba extrañamente mezclado lo verdadero y lo falso, tanto los amigos como los adversarios de la autoridad eclesiástica pudieron encontrar allí alguna cosa a su gusto [...] Del número de los pocos teólogos alemanes que desde el principio temieron de parte de Lutero grandes peligros para la Iglesia, fué el profesor de Ingolstadt, Juan Eck, el cual en sus Observaciones («Obelisci»), que sólo se esparcieron manuscritas, contra las tesis de Lutero, señalaba el parentesco de algunas de las opiniones por éste expresadas, con las doctrinas de Wiclef y de Huss, que ya la Iglesia había condenado" (Pastor, 1950:323-324).
}

Futhark 7 (2012)

Monreal, La perspectiva religiosa, 189-228

ISSN 1886-9300 
Meister» [QQuien construye junto al camino tiene muchos maestros»]. A continuación, Lutero hace el siguiente comentario:

«Es heißt: «Wer am Wege bauet, der hat viel Meister». Also gehet mir's auch. Diejenigen, die noch nie haben recht redden können, schweige denn dolmetschen, die sind allzumall meine meine Meister, und ich muß inr aller Junger sein»

(Luther, 1883:58).

["Se dice: "Quien construye junto al camino, tiene muchos maestros». Así me pasa también a mí. Aquellos que nunca han sabido hablar bien, ni mucho menos traducir, son siempre mis maestros, y yo debo ser discípulo de todos ellos"]

(Lutero, 2002:59).

En dicho proverbio, el término construir puede ser interpretado como realizar cualquier labor loable y que no debe ser merecedora del rechazo de quienes no cumplen con sus verdaderas obligaciones.

Lutero, ante las críticas recibidas y el no reconocimiento de su aportación a la traducción, dice que a él le está ocurriendo lo mismo que a San Jerónimo, cuando tradujo la Biblia:

"Also ging es St. Hieronimo auch, dar er die Biblia dolmetscht, da war alle Welt sein Meister. Er allein war es, der nichts kunnte, und urteileten dem guten Mann sein Werk diejenigen, so ihm nicht gnug gewest wären, daß sie ihm die Schuh hätten sollen wischen. Darun gehöret große Geduld dazu, so jemand etwas offentlich Guts tun will, denn die Welt will Meister klügin bleiben und mu $\beta$ immer das Ro $\beta$ unter dem Schwanz zäumen, alles meistern und selbs nichts können, das ist ihr Art, davon sie nicht lassen kann" Luther, 1883:60).

["Así le sucedió a San Jerónimo: cuando tradujo la Biblia, todo el mundo quiso ser su maestro, sólo él no sabía nada; y opinaban acerca de la obra del buen hombre aquellos que ni merecían limpiarle los zapatos. Por ello, el hacer algún bien público requiere mucha paciencia; pues todo el mundo quiere ser Maestro Listillo y coger constantemente el rábano por las hojas, dominar todo sin saber nada. Éste es su estilo, y no consiguen dejarlo"] (Lutero, 2002:61). 
Pese a la recepción crítica que tuvo la traducción de la Biblia en algunos sectores, no cabe duda que Lutero, por su forma de proceder en la traducción, como por los criterios que, a su entender, deben orientarla y, sobre todo, por haberse fijado como prioridad principal hacer la versión de los textos en alemán de modo que fueran accesibles a todos los alemanes, ha bien merecido el reconocimiento que por su labor le hace un notable alemán como Goethe:

"Tan sólo quisiera recordar aún, a favor de mi propuesta, la traducción de la Biblia de Lutero: pues que este hombre notable haya sabido transmitirnos en nuestra lengua materna como en una sola pieza una obra compuesta en los más variados estilos, con toda la diversidad de su tono poético, histórico, exhortativo e instructivo, ha beneficiado mucho más a la religión que si hubiera querido reproducir de forma independiente cada una de las peculiaridades del original". (Goethe, 1999:507) ${ }^{16 .}$

Dicho reconocimiento del lado alemán quiero complementarlo con otro testimonio, en este caso del académico de la Real Academia Española, ya fallecido, Valentín García Yebra, y gran filólogo y traductor, quien reconoce la labor de Lutero en el campo de la traducción con las siguiente palabras:

"Lutero, en este aspecto, fue un privilegiado. La masa blanda aún y maleable de la lengua alemana le permitía libertades de todo género, casi ilimitadas. Su genio lingüístico, robustecido por el trato asiduo con las tres grandes lenguas -griego, latín y hebreo- en que se gestó la cultura occidental; su talento musical y poético, y el amor apasionado que sentía por su propia lengua hicieron de su traducción de la Biblia el monumento más insigne hasta entonces de la prosa alemana, escrito en un estilo popular y artístico al mismo tiempo". (García Yebra, 1979:33-34)

\section{Conclusión general}

\footnotetext{
${ }^{16}$ En opinión de Johann Peter Eckermann, "Goethe -educado en el protestantismo y sin haber estudiado nunca en profundidad a Lutero-, siempre le tuvo en alta estima, recreándolo en su Götz von Berlichingen en la figura del hermano Martín. Apreciaba su labor como reformista que redimió a los alemanes del obscurantismo medieval y elogiaba la accesible simplicidad de su traducción de la Biblia." (Eckermann, 2005:935).
}

Futhark 7 (2012)

Monreal, La perspectiva religiosa, 189-228

ISSN 1886-9300 
A modo de conclusión queremos señalar que la trayectoria de vida que lleva a cabo Lutero, el papel tan relevante que juega en la Reforma Protestante y sus contribuciones a la lengua y a la traducción están guiados por un mismo hilo conductor: su perspectiva religiosa y la evolución que ésta sufre a lo largo de su existencia. Ella marca todo su itinerario personal, doctrinal y científico. Nos enfrentamos a un personaje que vive y desarrolla una existencia y actividad intensas, pero vividas y realizadas desde una lógica unitaria: su fe y doctrina reflejan y dan coherencia a todo lo que ha sido su convulsa vida personal, su lucha en la Iglesia y su aportación al desarrollo de la lengua alemana a través de su actividad de traducción de la Sagrada Escritura al alemán.

Por otra parte, también hay que decir que el protagonismo que asume Lutero en el proceso de la Reforma Protestante ha situado en un segundo plano su contribución al desarrollo de las lenguas en general y al alemán, en particular. No obstante, el tiempo ha ido confirmando -a través del estudio y la difusión de su obra- la importancia que de hecho ha tenido Lutero en el uso de la lengua alemana y en el campo de la traducción.

\section{Referencias bibliográficas}

Abellán, J., «Estudio Preliminar», en: Martín Lutero, Escritos Políticos. Madrid: Editorial Tecnos 1986, IX-XXXVII.

AlCALÁ, A., «Introducción», en: Miguel Server, Treinta cartas a Calvino. Sesenta signos del Anticristo. Apología de Melanchton. Madrid: Editorial Castalia 1981, 9-72.

Alonso Schökel, L. y Bravo, J.M., Apuntes de Hermeneútica, Madrid: Ediciones Trotta 1994.

ARANGUREN, J. L., «Prólogo. La primera noticia religiosa de la modernidad», en: HANS LILJE, Lutero. Barcelona: Salvat Editores 1986, 9-11.

Audin, M., Historia de Martín Lutero. Su vida, obras y doctrinas. Madrid: Imprenta de la Regeneración 1856.

Bello, E., «En el origen de la modernidad, la libertad: Giovanni Pico y Lutero», en: EDUARDO BELlo (ed.), Filosofía, sociedad e incomunicación. Homenaje a Antonio García Martínez. Murcia: Universidad de Murcia 1983, 33-57.

Biblia de Jerusalén (dir. A. Ubieta). Bilbao: Editorial Española Desclée de Brouwer 1967.

Futhark 7 (2012)

Monreal, La perspectiva religiosa, 189-228

ISSN 1886-9300 
Bogomilova, D., «Un enfoque hermenéutico de la traducción cultural», en: Revista Herméneus, n. ${ }^{\circ}$ 6, (2004), 19-39.

Breva-Claramonte, M., La didáctica de las lenguas en el Renacimiento. Bilbao: Universidad de Deusto 1994.

Burke, P., Lenguas y comunidades en la Europa moderna. Madrid: Akal, 2006.

CALVo, J. J., «Juan Luis Vives: ¿Un pionero de la traductología moderna? Apuntes sobre una discrepancia», en: Quaderns de Filología: Miscelànea Sanchis Guarner. Valencia: Universitat de Valencia, Vol. 2, 1984, 69-78.

Carrera de la Red, A., El problema de la lengua en el Humanismo renacentista español. Valladolid: Secretariado de Publicaciones de la Universidad de Valladolid, 1988.

Collinson, P., La Reforma. Barcelona: Debate 2004.

Eckermann, J. P., Conversaciones con Goethe. Barcelona: Acantilado 2005.

EGIDO, T., «Introducción general e Introducciones específicas», en: Martín Lucero, Obras. Edición preparada por T. Egido. Salamanca: Ediciones Sígueme 2006, 11-61.

Esteban, L. (ed.), Cuatro estudios a una obra o el "Arte de Enseñar"de Juan Luis Vives. Valencia: Ayuntament de Valencia 1997.

Gadamer, H-G., Verdad y Método. Salamanca: Ediciones Sígueme 2005.

García-Villoslada, R., Martín Lutero. Vol. II: En lucha contra Roma. Madrid: Biblioteca de Autores Cristianos (B.A.C.) 1971.

GaRcía YeBRA, V., «Lutero, traductor y teórico de la traducción», en: Revista Arbor Tomo Cll, n. ${ }^{\circ} 399$ Marzo (1979), 23-34.

Goethe, J. W., Poesía y Verdad. Barcelona: Alba Editorial 1999.

Gómez-Heras, J. M.G., Religión y Modernidad. La crisis del individualismo religioso de Lutero a Nietzsche. Córdoba: Publicaciones del Monte de Piedad y Caja de Ahorros de Córdoba 1986.

Grane, L., Modus Loquendi Theologicus. Luthers Kampf um die Erneuerung der Theologie (1515-1518). Leiden: E.J. Brill 1975.

Janssen, J., Historia Universal.Vol. VIII bis: La cultura alemana antes y después de Lutero. Barcelona: Librería Religiosa 1925.

KRIPPENDORFF, K., Metodología de análisis de contenido. Barcelona: Ediciones Paidós, 1997. 
Kusukawa, S. (ed.), Philip Melanchthon. Orations on Philosophy and Education. Cambridge: Cambridge University Press 1999.

LILJE, H., Lutero. Barcelona: Salvat Editores 1986.

LORTZ, J., Historia de la Reforma, I.. Madrid: Taurus 1963.

LUTERo, M., Carta sobre el arte de traducir y sobre la intercesión de los santos. Edición y traducción de T. Brandenberger. Madrid: Caparrós Editores 2002.

- Obras. Edición preparada por T. Egido. Salamanca: Ediciones Sígueme 2006.

LUther, M., Werke. Kritische Gesamtausgabe. Weimar: 1883 t. 30/2, ser. I. (=ed. Nürnberg, Johan Stüchs, 1530). Este texto se contiene en la edición y traducción de la edición bilingüe hecha por Tobias Brandenberger y publicada por Caparrós Editores, 2002. La paginación corresponde a esta edición bilingüe.

MORENO, V., «Reflexiones sobre la recepción de Luis Vives en España», en: Revista Res Publica, n. ${ }^{\circ}$ 20, (2008), 43-66.

Oberman, H. A., Lutero. Un hombre entre Dios y el diablo. Madrid: Alianza Universidad, 1992.

O’NeILL, J., Martín Lutero. Madrid: Akal, 1991.

Ortega y Gasset, J., Miseria y esplendor de la traducción. München: Langewiesche-Brandt 1956.

PAstor, L., Historia de los Papas en la época del Renacimiento y desde la Reforma, desde la elección de León $X$ hasta la muerte de Clemente VII. Volumen VII. Barcelona: Gustavo Gili 1950.

PEnA, P., Las fuentes de la teología en Felipe Melanchton. Su doctrina sobre los lugares teológicos comparada con la doctrina católica de $M$. Cano y la tradición medieval (Tesis). Salamanca: Universidad Pontificia de Salamanca 2002.

Peñalver, P., La mística española (siglos XVI y XVII). Madrid: Akal Ediciones 1997.

RIQUER DE M. Y VALVERDE, J. M., Historia de la literatura universal. Volumen 5: Reforma, Contrarreforma y Barroco. Barcelona: Editorial Planeta 1984.

RiverA, A., Republicanismo calvinista. Murcia: Diego Marín Librero-Editor, 1999. 
Romo, F., «De Lutero a Gadamer: De la hermeneútica a la estética», en: L. Beltrán e I. DUQUE, Palabras de viaje: estética y hermeneútica del viaje. Bellcaire d’Empordá: Vitella 2007, 19-42.

RupP, H.F., «Philipp Melanchton (1497-1560)», en: Revista Perspectivas. Vol. XXVI, nº 3, Septiembre, (1996), 659-669.

Sala, R., «Introducción», en: Johann Wolfgang Goethe, Poesía y Verdad. Barcelona: Alba Editorial 1999, 11-21.

Steiner, G., Después de Babel. Madrid: Fondo de Cultura Económica 1981.

VIDAL, C., Caso Lutero. Madrid: EDAF, 2008.

Villacañas, J.L., «El final de la Edad Media», en: Revista Res Publica, n. ${ }^{\circ}$ 19, (2008), 75-103.

Weber, M., La ética protestante y el espíritu del capitalismo. Edición de Jorge Navarro y Prólogo de José Luis Villacañas. Madrid: Ediciones ISTMO 1998. 
